\title{
A Role for CD154, the CD40 Ligand, in Granulomatous Inflammation
}

\author{
Julien Villeneuve, ${ }^{1}$ Alexis Desmoulière, ${ }^{2}$ Antoine Dewitte, ${ }^{3}$ Nelly Bordeau, ${ }^{2}$ \\ Pierre Costet, ${ }^{4}$ Laia Bassaganyas, ${ }^{5}$ Jean-Christophe Fricain, ${ }^{6}$ Jean Ripoche, ${ }^{6}$ and \\ Sébastien Lepreux ${ }^{6,7}$
}

\author{
${ }^{1}$ Cell and Developmental Biology Department, Centre for Genomic Regulation (CRG), The Barcelona Institute for Science and \\ Technology, 08003 Barcelona, Spain \\ ${ }^{2}$ EA 6309 and Department of Physiology, Faculty of Pharmacy, University of Limoges, 87000 Limoges, France \\ ${ }^{3}$ Service d'Anesthésie-Réanimation II, CHU de Bordeaux, 33000 Bordeaux, France \\ ${ }^{4}$ Service des Animaleries, Université de Bordeaux, 33000 Bordeaux, France \\ ${ }^{5}$ Cardiovascular Research Institute and Institute for Human Genetics, University of California, San Francisco, CA, USA \\ ${ }^{6}$ INSERM U1026, Université de Bordeaux, 33000 Bordeaux, France \\ ${ }^{7}$ Pathology Department, CHU de Bordeaux, 33000 Bordeaux, France
}

Correspondence should be addressed to Julien Villeneuve; julienvilleneuve81@gmail.com

Received 19 February 2017; Revised 10 June 2017; Accepted 15 June 2017; Published 12 July 2017

Academic Editor: Tânia Silvia Fröde

Copyright (c) 2017 Julien Villeneuve et al. This is an open access article distributed under the Creative Commons Attribution License, which permits unrestricted use, distribution, and reproduction in any medium, provided the original work is properly cited.

\begin{abstract}
Granulomatous inflammation is a distinctive form of chronic inflammation in which predominant cells include macrophages, epithelioid cells, and multinucleated giant cells. Mechanisms regulating granulomatous inflammation remain ill-understood. $\mathrm{CD} 154$, the ligand of CD40, is a key mediator of inflammation. CD154 confers a proinflammatory phenotype to macrophages and controls several macrophagic functions. Here, we studied the contribution of CD154 in a mouse model of toxic liver injury with carbon tetrachloride and a model of absorbable suture graft. In both models, granulomas are triggered in response to endogenous persistent liver calcified necrotic lesions or by grafted sutures. CD154-deficient mice showed delayed clearance of carbon tetrachloride-induced liver calcified necrotic lesions and impaired progression of suture-induced granuloma. In vitro, CD154 stimulated phagocytosis of opsonized erythrocytes by macrophages, suggesting a potential mechanism for the altered granulomatous inflammation in CD154KO mice. These results suggest that CD154 may contribute to the natural history of granulomatous inflammation.
\end{abstract}

\section{Introduction}

The clearance of undesirable material is a required checkpoint in the cascade of events that follows tissue injury and ends in the resolution of inflammation and tissue repair $[1,2]$. This clearance step allows the removal of signals that would otherwise perpetuate inflammation. Granulomatous inflammation is a distinctive pattern of chronic inflammation in response to various infectious agents, such as mycobacteria or fungi, to noninfectious agents, as exemplified in the foreign body reaction (FBR) to biomaterials and in conditions from unknown causes including vasculitis, sarcoidosis, and Wegener's granulomatosis; predominant cells in granulomatous inflammation include macrophages, epithelioid cells, and multinucleated giant cells (MGCs) [3-15]. MGCs are macrophage polykaryons resulting from macrophage fusion [16]. Mechanisms responsible for MGC generation, as well as the functional significance of MGCs, remain incompletely understood [7, 17]. Apart from macrophages and MGCs, other cells, including $\mathrm{T}$ cells 
and fibroblasts, contribute to the progression of infectious or noninfectious granulomatous inflammation. A complex set of mediators is produced during the different phases of granulomatous inflammation, but a clear understanding of how these mediators orchestrate granulomatous progression is lacking. Cytokines, including interleukin- (IL-) 4, IL-12, IL-13, and interferon- (IFN-) $\gamma$, as well as matrix proteins and matrix remodeling proteins, including vitronectin, osteopontin, fibronectin, or matrix metalloproteinase- (MMP-) 9, have been shown to contribute [8, 18-28]. Angiogenesis is also a key event in granulomatous inflammation, and angiogenesis regulators are important contributors [29, 30]. The FBR is critical in biomaterial research as it negatively influences the integration of implanted devices and against which various strategies are actively sought for [12, 13, 31-36].

Platelet-derived mediators are likely to be involved in granulomatous inflammation. Indeed, the integral role of platelets in controlling several facets of the innate immune response is now being fully appreciated [37]. Activated platelets release a large array of inflammatory and mitogenic bioactive mediators with pleiotropic effects on target cells, including chemotaxis, adhesion, cell survival, and proliferation [38-41]. Platelets also stand at the cross-road of several proteolytic cascades linked with inflammation, such as coagulation and complement cascades [42]. Platelets are activated at sites of tissue injury, and implanted foreign materials activate platelets. However, mechanisms remain to be fully understood $[12,43,44]$. Among platelet mediators, CD154, a member of the tumor necrosis factor superfamily, may play a role in granulomatous inflammation. Indeed, the interaction between CD154 and its receptor CD40 controls a wide range of immune and inflammatory responses [40, 45-48]. CD40 is widely distributed, and mononuclear phagocytes express CD40 [49-52]. CD40 ligation by CD154 has consequences on inflammation, coagulation, extracellular matrix remodeling, metabolism, cell growth, and survival $[45,46]$. Activated $\mathrm{CD}^{+} \mathrm{T}$ cells, activated platelets, and various other cells can be the source of CD154 [46]. Platelets represent a primary reservoir of CD154 in the blood [53-55].

CD40 triggering on macrophages has a profound effect on their biology, directing them towards an activated phenotype. CD40 signals macrophage functions for a large part towards expression of genes involved in proinflammatory response and tissue remodeling [52]. CD40 triggering noticeably induces the expression of a range of cytokines and chemokines, tissue factor, and MMPs, including MMP-1, MMP-3, MMP-9, MMP-11, and MMP-12, by macrophages and enhances IFN $\gamma$-induced production of nitric oxide $[45,51,52,56-64]$. Accordingly, T cell-mediated activation of macrophages to produce nitric oxide or cytokines is impaired in the CD154-deficient mouse [57]. Therefore, CD40 signaling could be foreseen to control either directly or indirectly the macrophagic response in granulomatous inflammation.

Here, we studied the role of CD154 in granulomatous inflammation in two models of noninfectious granulomatous inflammation, a model of carbon tetrachloride- $\left(\mathrm{CCl}_{4^{-}}\right)$ induced liver injury and a model of absorbable suture graft.
In these models, a granulomatous inflammation is triggered, in response to persistent liver calcified necrotic lesions or in response to the grafted biomaterial. We studied the progression of the granulomatous inflammation in wild-type (WT) and CD154-deficient mice (CD154KO). We also analyzed the role of CD154 on macrophage phagocytosis in vitro.

\section{Material and Methods}

2.1. Mice. Male Balb/cByJ CD154KO mice were generated from male Bl6/C CD154KO (B6.129S2-CD40lg ${ }^{\text {tm1Imx} / J) ~}$ mice (Jackson Laboratory, ME) by repeated ( $>10)$ backcrossings. Animals were housed in a temperature-controlled pathogen-free environment (transgenic animal housing of Bordeaux University) with a $12 \mathrm{~h}$ light/dark cycle and given free access to food and water. The study followed the guidelines of the animal research ethical committee of Aquitaine Poitou-Charentes. Comparative blood counts showed no significant differences between WT and CD154KO animals (Supplementary experimental procedures available online at https://doi.org/10.1155/2017/2982879).

2.2. Carbon Tetrachloride Model. A dose of $300 \mu \mathrm{L} / \mathrm{kg}$ body weight $\mathrm{CCl}_{4}(6 \%(v / v)$ solution in olive oil (olive oil for human consumption Puget ${ }^{\circledR}$, France)) was injected intraperitoneally three times a week [65]. Eight mice were used at time 0,4 at 1 injection, 4 at 2 injections, 8 at 3 injections, and 8 at 9 injections, for each group of mice.

2.3. Suture Bundle Grafts. Bundles of ten purple absorbable polyglactin 910 suture threads (Vicryl 0, Ethicon, Issyles-Moulineaux, France), a synthetic poly(D,L-lactide-coglycolide) (PLGA) copolymer [66-68], were implanted in the subcutaneous tissues on each mouse back; to track the implantation site, one thread of black nonabsorbable polyamid suture (Monosoft 0, Syneture, Covidien, France) was added within the bundles (Supplementary Figure 1). In experiments comparing WT and CD154KO mice, a total of 6 bundles were processed for each group.

2.4. Histology and Immunohistochemistry. $\mathrm{CCl}_{4}$ experiments: mice were sacrificed 48 hours after $1,2,3$, or $9 \mathrm{CCl}_{4}$ intraperitoneal injections. Liver samples were harvested, rapidly sliced to obtain sections from several lobes, and fixed in $3.7 \%$ formaldehyde. Paraffin-embedded liver sections $(5 \mu \mathrm{m})$ were stained with hematoxylin-eosin (HE) to evidence necrosis and cellular inflammation or with von Kossa stain to evidence calcifications. Immunohistochemical staining was performed with a rat anti-mouse F4/80 (AbD Serotec, UK). After heat-induced antigen retrieval (in citrate buffer, $\mathrm{pH}$ 6), endogenous peroxidases were inhibited. Then, liver sections were incubated with primary antibodies at a $1 / 100$ dilution, for 1 hour at room temperature. The signal was amplified by the EnVisionTM dextran polymer (Dako A/S, Trappes, France) and revealed with liquid diaminobenzidine substrate (Dako A/S) before counterstaining with hematoxylin.

Suture bundle experiments: animals were sacrificed at week intervals. Because suture contained a nonabsorbable thread, at each time point of the experiment, the 
implantation sites on the back of the mice can be localized and removed en bloc. They were fixed in 3.7\% formaldehyde, divided in four parts perpendicularly to the axis of the residual nonabsorbable thread, and paraffin embedded. Five serial sections $(3 \mu \mathrm{m})$ were performed on each paraffinembedded bloc (Supplementary Figure 1B). Areas containing knots were excluded from the quantification. Each slide was stained with Masson's trichrome staining. With this staining, extracellular matrix is stained in green and the cytoplasm of the cells is stained in purple. Taking advantage of the contrast provided by this staining between the granuloma and the extracellular matrix, the granulomatous lesions of FBR can be easily outlined on the numerical microphotography taken with a camera-equipped light microscope and the area was quantified using the calibrated NIS-Elements Imaging software (Nikon France).

2.5. Liver Enzyme Measurements. Blood samples were collected from each animal by vein puncture before sacrifice. Sera were stored at $-80^{\circ} \mathrm{C}$ until measurements of albumin, bilirubin, alkaline phosphatase (ALP), gammaglutamyltransferase $(\gamma$-GT), aspartate aminotransferase (ASAT), and alanine aminotransferase (ALAT) on an automated analyzer in the Biochemistry Department of Pellegrin Hospital, Bordeaux, France.

2.6. Macrophages and Multinucleated Giant Cells. Macrophages and MGCs were obtained in vitro, as previously described [69]. Briefly, human mononuclear cells were obtained from platelet/leukocyte concentrates from healthy donors (convention with Etablissement Français du Sang Aquitaine-Limousin, Bordeaux, France) by centrifugation on a Ficoll gradient (Ficoll-Paque PLUS, GE Healthcare Life Sciences) and were suspended in complete medium Dulbecco's modified Eagle's medium supplemented with $10 \%$ heat-inactivated fetal calf serum (Perbio Science, Cramlington, UK), $2 \mathrm{mM}$ L-glutamine (Invitrogen, Cergy Pontoise, France), $100 \mathrm{IU} / \mathrm{mL}$ penicillin (Invitrogen), and $100 \mu \mathrm{g} / \mathrm{mL}$ streptomycin (Invitrogen). Cells were seeded in Primaria ${ }^{\circledR}$ 96-well tissue culture plates (VWR, Strasbourg, France) at $2.5 \times 10^{5}$ cells per well in $100 \mu \mathrm{L}$ of culture medium. After 1 hour, nonadherent cells were removed by five washings; wells were then added with medium supplemented with granulocyte macrophage colony-stimulating factor (GM-CSF) (100 ng/mL) (Immunotools, Friesoythe, Germany) and the culture was maintained for two weeks. MGCs were generated by IL-4-dependent macrophage fusion: medium supplemented with GM-CSF $(100 \mathrm{ng} / \mathrm{mL})$ and IL-4 (100 ng/mL) (Immunotools) was added at day 7, and the culture was maintained for 15 additional days.

2.7. Real-Time RT-PCR Analysis. Total RNA was extracted from $50 \mathrm{mg}$ of mouse frozen liver using a RNA extraction kit (NucleoSpin ${ }^{\circledR}$ RNAII Macherey-Nagel, Hoerdt, France) following the manufacturer's instructions and quantified spectrophotometrically (Thermo Spectronic, Cambridge, UK) from absorbance at $260 \mathrm{~nm}$. To ascertain the purity of the extracted RNA, the $260 \mathrm{~nm} /$ $280 \mathrm{~nm}$ ratio was measured, and the $18 \mathrm{~S}$ and $28 \mathrm{~S}$ components were visualized on agarose gel electrophoresis. Complementary DNA (cDNA) was synthesized with oligo-dT from $2 \mu \mathrm{g}$ of total RNA in a final volume of $40 \mu \mathrm{L}$ using First Strand cDNA Synthesis Kit for RTPCR (Roche Applied Sciences, Meylan, France) according to the manufacturer's instructions.

The quantitative PCR was performed in triplicate on a Mx4000TM Multiplex Quantitative PCR System (Stratagene, Amsterdam, Netherlands) using $\mathrm{iQ}^{\mathrm{TM}} \mathrm{TMSYBR}^{\circledR}$ Green Supermix kit (Bio-rad, Marnes la Coquette, France). The cycling parameters for quantitative PCR reaction included 40 cycles of denaturation at $95^{\circ} \mathrm{C}$ for 30 seconds, annealing at $62^{\circ} \mathrm{C}$ for 60 seconds, and elongation at $72^{\circ} \mathrm{C}$ for 30 seconds. The specificity of quantitative PCR was established by incorporating no reverse transcribed RNA. The specificities of the amplified transcripts were confirmed by melting curve profiles generated at the end of the PCR program and by sequencing. Mouse CD40 primers were as previously described [70]. Oligonucleotides used in this study are described in Supplementary experimental procedures. Ribosomal phosphoprotein P0 was used as a housekeeping gene standard.

2.8. Immunofluorescence. Cells were fixed by adding an equal volume of $2 \%$ paraformaldehyde (PFA). After $30 \mathrm{~min}$ at room temperature, Triton X-100 $(0.1 \% v / v)$ was added for $5 \mathrm{~min}$. Fixed and permeabilized cells were washed 3 times in phosphate-buffered saline, pH 7.2 (PBS), blocked 45 min in $\mathrm{PBS} / 1 \%$ bovine serum albumin (BSA) (Sigma Aldrich, France), and incubated for 1 hour with an anti-human CD40 mouse antibody (mAb89, a kind gift from Dr. J. Banchereau, Dallas) in a humidified chamber. Slides were washed 3 times in $\mathrm{PBS} / 1 \% \mathrm{BSA}$ and incubated for 1 hour with a cross-adsorbed Alexa Fluor 488 goat anti-mouse $\operatorname{IgG}(\mathrm{H}+\mathrm{L})$ (Interchim, Montluçon, France) at a $1 / 200$ dilution in PBS/1\% BSA. 4',6' Diamidino-2-phenylindole (DAPI) (Merck, Darmstadt, Germany) was used to stain nuclei and mounted with Vectashield (Vector Laboratories Inc., Burlingame, CA). Negative controls included indirect labeling with a primary isotype-matched mouse IgG followed by secondary antibody. Samples were visualized using a Leica SP5 confocal microscope (Leica Microsystèmes SAS, Rueil Malmaison, France).

2.9. Phagocytosis Assay. Macrophage and MGC phagocytosis of opsonized erythrocytes were assayed using the CytoSelect 96-well phagocytosis assay (Euromedex, Mundolsheim, France) following manufacturer's instructions. Briefly, cells were incubated with or without recombinant soluble CD154 (rsCD154) (MegaCD40LTM, Coger SAS, Paris, France) at $200 \mathrm{ng} / \mathrm{mL}, 24$ hours before the addition of IgG opsonized sheep erythrocytes. Supernatants were aspirated after 15, 30, 60, and $120 \mathrm{~min}$, and cells were washed with PBS to remove nonphagocytized erythrocytes. Adherent cells were then lysed, and the amount of phagocytized material was quantitated by a colorimetric assay. Negative control cells were treated with $2 \mu \mathrm{M}$ cytochalasin D to block phagocytosis. 
2.10. Tartrate-Resistant Acid Phosphatase Activity Detection. Acid phosphatase activity in the presence of $50 \mathrm{mM}$ tartrate was assayed with naphtol AS-MX phosphate (Sigma) as a substrate and freshly prepared Fast Violet B (Sigma). Liver sections were incubated overnight at $4^{\circ} \mathrm{C}$ in the substrate solution and counterstained with von Kossa. Cells were considered positive when evidencing strong pink staining with numerous red granules spread throughout the cytoplasm.

2.11. Statistics. Data are presented as means \pm SD. Statistical comparisons between groups were performed using the Wilcoxon signed rank test. $p<0.05$ was taken to imply statistical significance.

\section{Results}

3.1. CD154 Is Required for the Clearance of Liver Calcified Necrotic Lesions in Carbon Tetrachloride-Treated Mice. To investigate the contribution of $\mathrm{CD} 154$ in granulomatous inflammation, we studied a murine model of endogenous lesions in WT and CD154KO mice. We used a murine model of liver calcified necrotic lesions induced by $\mathrm{CCl}_{4}$ administration. The $\mathrm{CCl}_{4}$ model has proven useful for the study of liver repair mechanisms; deficiencies in c-met signaling, plasminogen, and urokinase-type plasminogen activators lead to an impaired liver repair characterized by a delayed resolution of the granulomas around dystrophic calcified areas [71-73]. Hepatic expression of CD40 and liver histology did not differ between both mouse strains (Figures 1(a) and 1(b)). Parenchymal centrilobular necrosis was observed following the first $\mathrm{CCl}_{4}$ injection; the extent and the topographic distribution of necrotic lesions were similar in both strains (Figure 1(c)). Plasma liver enzyme measurements confirmed ongoing cytolysis and a similar magnitude of the liver injury between both mouse strains (Figure $1(\mathrm{~g})$ ). Following the second $\mathrm{CCl}_{4}$ injection, the general pattern of liver parenchymal necrosis remained unchanged but necrotic areas were infiltrated by inflammatory cells. There were no morphological differences in the inflammatory cell recruitment between both strains (Figure 1(d)). After three $\mathrm{CCl}_{4}$ injections, necrotic lesions, with apparent basophilic amorphous granular deposits of dystrophic calcifications surrounded by granulomas, were discernible in centrilobular regions of both strains (Figure 1(e)). Von Kossa staining confirmed calcium deposition within necrotic areas in both mouse strains (Figures 2(a), 2(b), and 2(c)); granulomas consisted of macrophages and MGCs, distributed throughout calcification (Figure 2(c)). The magnitude of parenchymal lesions was similar after three $\mathrm{CCl}_{4}$ injections; however, there was a divergence after nine $\mathrm{CCl}_{4}$ injections, with reference to the extent of dystrophic calcified necrotic areas. They persisted in CD154KO mice, whereas they had almost disappeared in WT mice (Figures 1(f) and 2(d)). Macrophages and MGCs associated to calcifications expressed the F4/80 antigen (Figure 3(a)). The quantification of F4/ 80 messenger RNA expression suggested similar macrophagic cell recruitment following $\mathrm{CCl}_{4}$-induced liver injury (Figure 3(b)). As IL-4 participates to foreign body giant cell generation in vivo, and as it is induced by CD154, we measured IL- 4 expression by qRT-PCR in the livers of WT and $\mathrm{CD} 154 \mathrm{KO}$ mice following $\mathrm{CCl}_{4}$ administration. IL-4 expression increased after nine $\mathrm{CCl}_{4}$ injections, but there were no differences between both strains (Figure 3(c)). MCP-1 has also been implicated as promoting macrophage fusion; its expression did not show differences between WT and CD154KO mice following $\mathrm{CCl}_{4}$ treatment (Figure 3(d)). The expression of other cytokines tested, IL-6 and MIP-2, also increased during the course of the $\mathrm{CCl}_{4}$ administration but there were no significant differences between WT and CD154KO, except for MIP-2 that showed reduction after 9 injections (Figures 3(e) and 3(f)). Finally, as osteoclasts also result from monocyte fusion and are involved in the resorption of calcified bone matrix, we also excluded the possibility that MGC associated with the dystrophic calcified areas could be osteoclasts by the absence of tartrate-resistant acid phosphatase activity; further, the expression of mRNAs for the receptor activator of NF-kB (RANK) and its ligand, a crucial dyad for the induction of osteoclasts, were not induced following $\mathrm{CCl}_{4}$ administration as well as for the expression of osteoprotegerin mRNA, a competitive RANK inhibitor (data not shown). Altogether, these results suggested impediment in the clearance of calcified necrotic lesions in CD154KO mice.

3.2. The Resolution of the Foreign Body Granuloma Is Altered in CD154KO Mice. In an effort to strengthen these results, we developed a model of granuloma generated against implanted foreign material, a PLGA suture graft (Supplementary Figure 1 and Figure 4). Sutures represent one if not the most widely used biomaterial. Copolymers between glycolic acid and lactic acid have found large medical applications in surgical implants and also in biopolymer research as they represent promising scaffolds for cell support in tissue-engineering or drug-delivery devices [74]. Suture bundles were resorbed between weeks 8 and 10 postimplantation; the kinetic of resorption followed a sharp sigmoid inflection between weeks 8 and 10 postimplantation, after a lag phase of 6 weeks during which no significant variations of the bundle sizes were apparent (Figure 4). Morphologically, the host reaction had the form of typical granulomas, as expected [66-68]. After an initial acute inflammatory step, suture threads were progressively outlined by connective tissue and colonized by macrophagic cells. The FBR was characterized by granulomas containing numerous mononuclear macrophages, some MGCs and sparse lymphocytes. Between weeks 8 and 10, suture threads were cleared, leaving the nonabsorbable thread in the center of a residual granuloma at week 10 (Figure 4). Thus, week 10 was used as time point to compare the resorption of suture bundles between WT and CD154KO mice. Skin histology did not differ between both mouse strains. In both mouse strains, granulomas contained macrophages and MGCs as revealed by F4/80 staining (Figures 5(a), 5(b), 5(c), 5(d), $5(\mathrm{e})$, and 5(f)). However, the FBR area was larger in CD154KO mice compared to WT mice (Figure 5(g)). These results suggested an altered clearance of sutures bundles in CD154KO mice. 


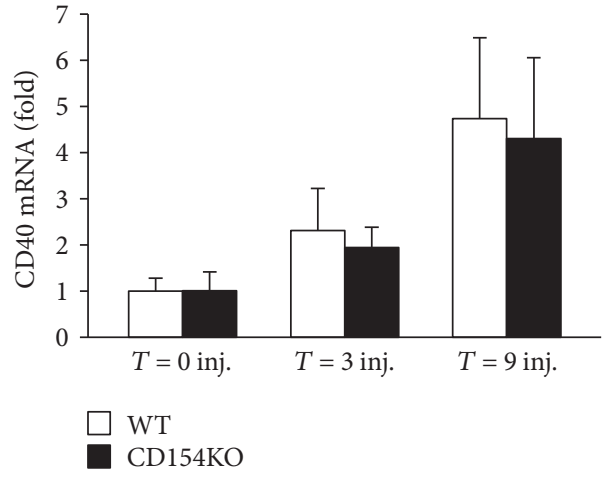

(a)

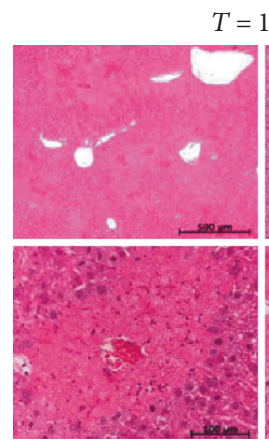

WT



WT
$T=1$ inj.

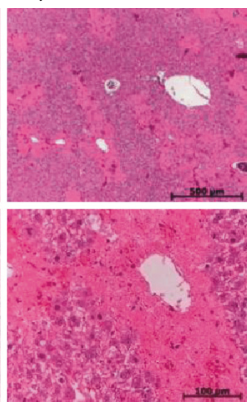

CD154KO

(c)

$=3$ inj.
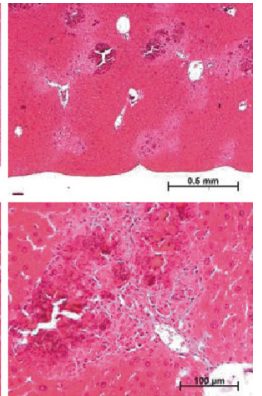

CD154KO

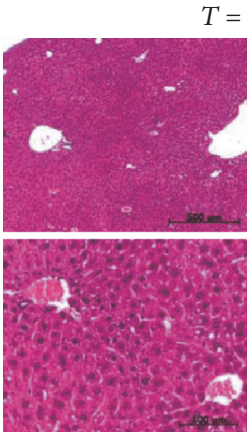

WT

$T=0$ inj.

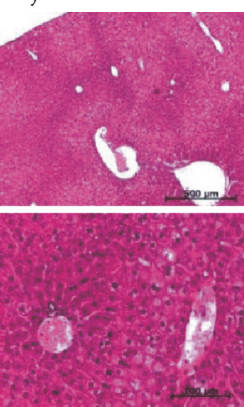

CD154KO

(b)

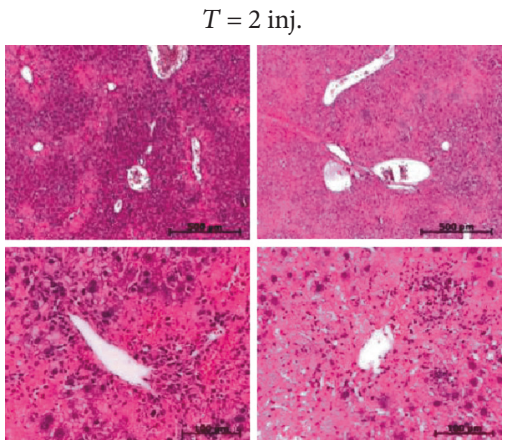

CD154KO

(d)

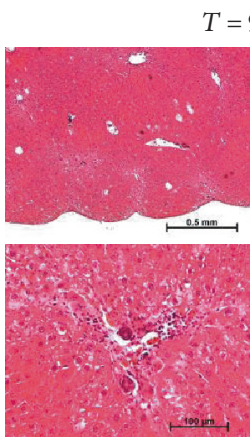

WT

$=9$ inj.

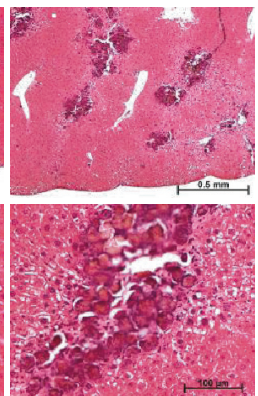

CD154KO

(e)

(f)

\begin{tabular}{lcc}
\hline & $\mathrm{WT}$ & $\mathrm{KO}$ \\
\hline Albumin & $33 \pm 1$ & $33 \pm 2$ \\
Bilirubin & $4 \pm 1$ & $4 \pm 1$ \\
ALP & $180 \pm 32$ & $171 \pm 34$ \\
$\gamma$-GT & 0 & 0 \\
ASAT & $937 \pm 236$ & $912 \pm 210$ \\
ALAT & $2798 \pm 1253$ & $2215 \pm 1241$ \\
\hline
\end{tabular}

(g)

Figure 1: Carbon tetrachloride liver injury progression in WT and CD154KO mice. (a) Relative levels of CD40 mRNA expression (arbitrary units) in the liver of WT and CD154KO mice at time 0 and after 3 and 9 intraperitoneal $\mathrm{CCl}_{4}$ injections (mean $\pm \mathrm{SD}, n=8$ ). Representative HE-stained liver tissue sections of WT and CD154KO mice at time 0 (b) and after 1 (c), 2 (d), 3 (e), and 9 (f) intraperitoneal CCl injections (inj.). Top panels, low magnifications (scale bar $500 \mu \mathrm{m}$ ); bottom panels, high magnifications (scale bar $100 \mu \mathrm{m}$ ); $(n=8$ at time $0, n=4$ at 1 injection, $n=4$ at 2 injections, $n=8$ at 3 injections, and $n=8$ at 9 injections for each group of mice). (g) WT and CD154KO mice show similar hepatic cytolytic response after $\mathrm{CCl}_{4}$ administration. Serum measurements of albumin (gL), bilirubin $(\mu \mathrm{mol} / \mathrm{L})$, and liver enzymes (IU/L) after $1 \mathrm{CCl}_{4}$ injection in WT and $\mathrm{CD} 154 \mathrm{KO}$ mice (mean $\pm \mathrm{SD}, n=5$ ). 

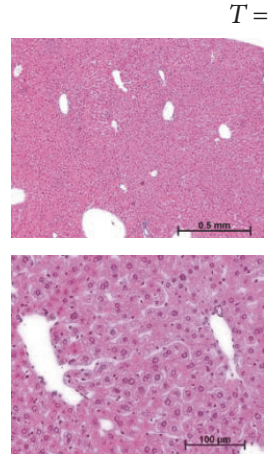

WT



WT
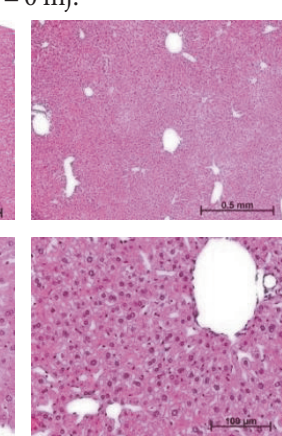

CD154KO

(a)

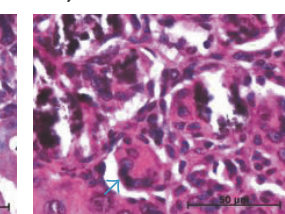

CD154KO

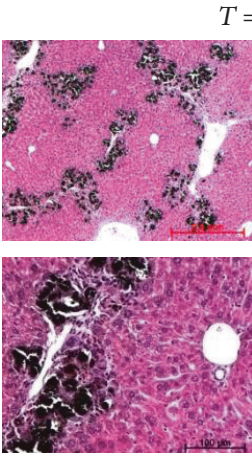

WT
$T=3$ inj.
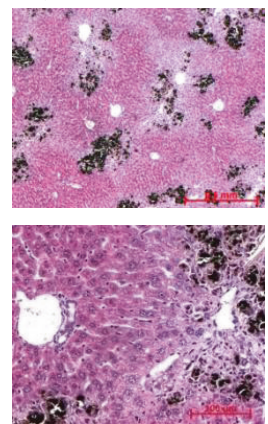

CD154KO

(b)

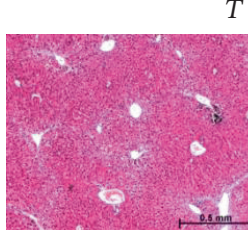

$T=9$ inj.

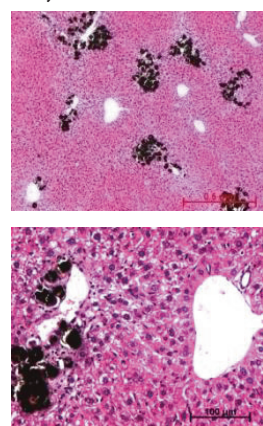

CD154KO

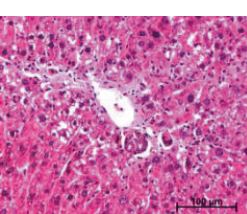

WT

(c)

(d)

FIgURE 2: Differential clearance of dystrophic calcified necrotic liver lesions in WT and CD154KO mice: von Kossa staining. Representative

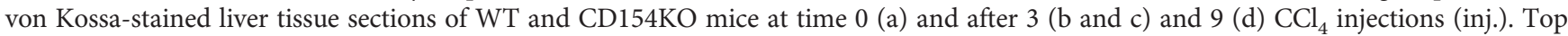
panels, low magnifications (scale bar $500 \mu \mathrm{m}$ ); bottom panels, high magnifications (scale bar $100 \mu \mathrm{m}$ ); $(n=8$ for each condition in each group of mice). (c) High magnifications (scale bar $50 \mu \mathrm{m}$ ) from (b) ( $T=3$ injections), highlighting MGCs associated to dystrophic calcified areas (arrows).

3.3. CD154 Stimulates Phagocytosis by Macrophages. Macrophage recruitment, adhesion to necrotic/calcified or foreign material, activation, and fusion of macrophages are key steps in granulomatous inflammation and FBR [12]. Signals that control macrophage phenotype and function are numerous, cytokines playing an important role. As CD40 triggering in macrophages leads to the induction of a pleiotropic range of effectors, including cytokines/chemokines and adhesion molecules, it could be hypothesized that CD154 interferes at various steps in granulomatous inflammation. First, we reexamined CD40 expression on macrophages and on MGCs. MGCs were generated by IL-4-mediated fusion [69]. In the absence of IL-4, macrophagic cells remained scattered; upon IL-4 treatment, they fused together forming MGCs harboring nucleus numbers which ranged from 20 to 40 admixed with scattered remaining macrophages; both macrophages and IL-4-induced MGCs expressed CD40 (Figures 6(a) and 6(b)). The addition of rsCD154 neither increased the frequency nor the size of MGCs, nor altered cell morphology, suggesting that it had no effect on the cell fusion process (data not shown). As essential key step in the resolution of the inflammatory reaction is the phagocytic clearance by macrophagic cells, we investigated whether
CD154 has a regulatory action on phagocytosis. As expected [75], isolated human macrophages ingested IgGopsonized erythrocytes. The presence of rsCD154 in cultured macrophages resulted in increased phagocytosis of opsonized red cells (Figure 6(c)). Phagocytosis of IgG-opsonized erythrocytes was also observed in cultures associating MGCs, and macrophages after IL-4-mediated fusion and rsCD154 had a stimulatory effect (Figure 6(d)), a situation that would more closely represent the admixed MGCs and macrophages granuloma cell population. However, as cultures of MGCs also include scattered macrophages, whether CD154 stimulates MGC phagocytosis needs confirmation in isolated MGC cultures.

\section{Discussion}

Although conditions leading to granulomatous inflammation are diverse, there are common histologic features and mechanisms in granuloma generation. An intricate array of cell and biological mediators coordinate in an ill-defined way the progression of granulomatous inflammation $[4,10]$. In this work, we show that, in two different models of 


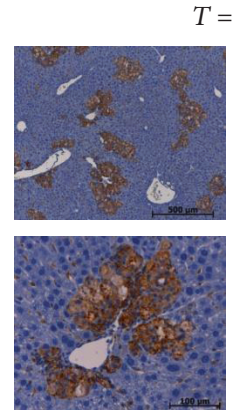

WT
$T=3$ inj.
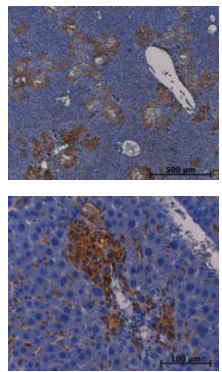

CD154KO
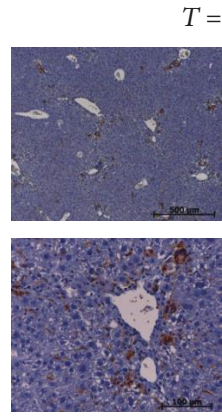

WT

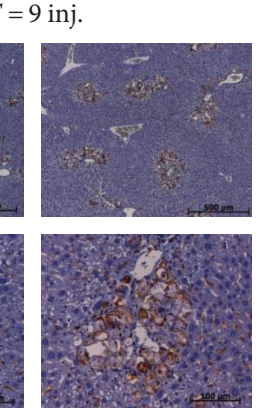

CD154KO

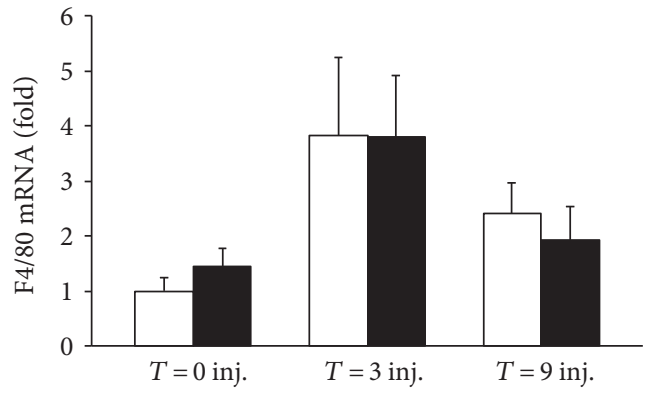

$\square$ WT (a)

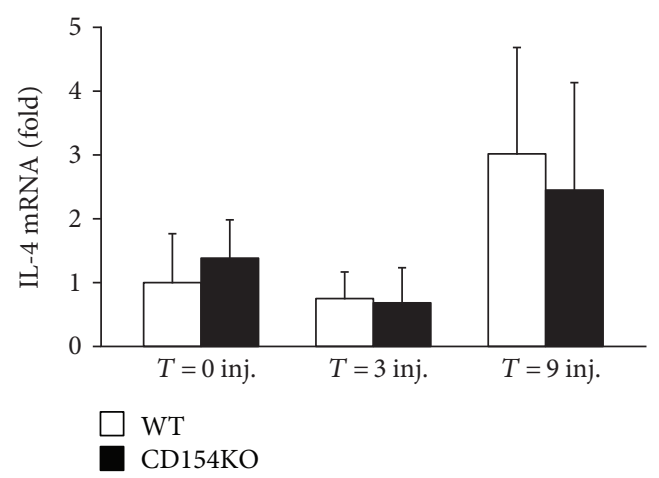

(c)

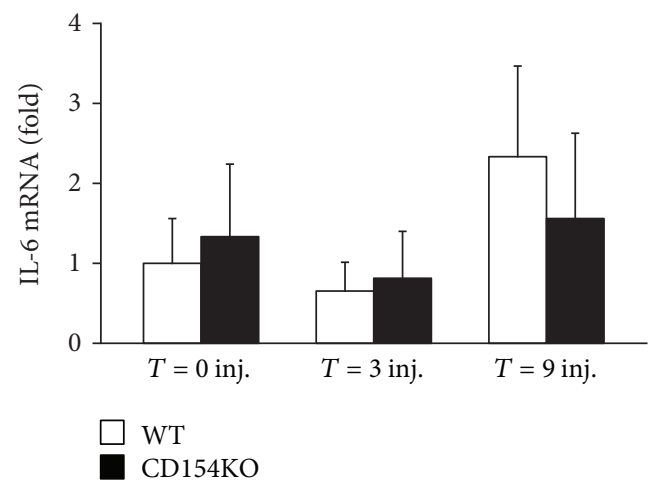

(e)

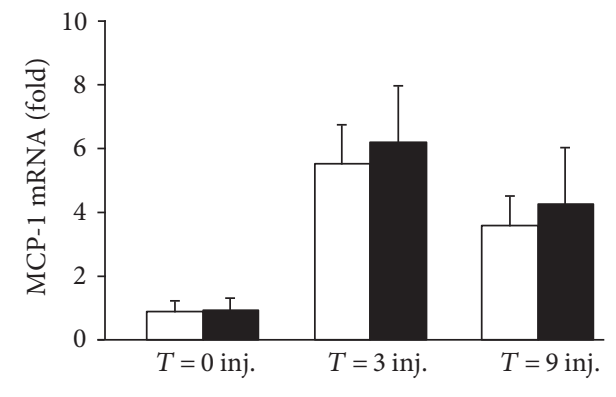

$\square$ WT

CD154KO

(d)

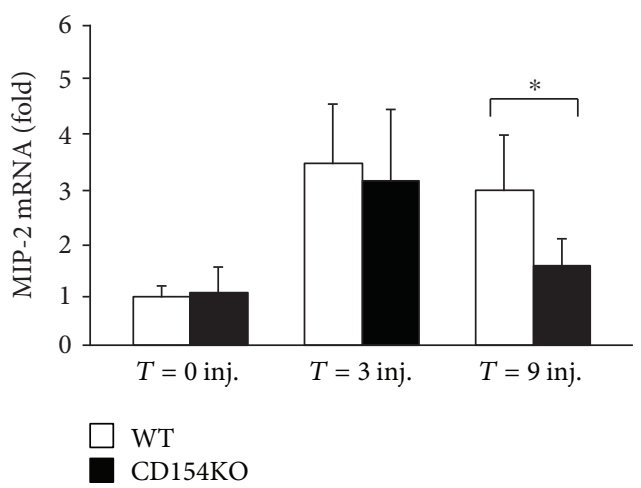

(f)

FIGURE 3: Immunohistochemical staining of monocyte/macrophage cells and cytokine/chemokine expression in WT and CD154KO mice after $\mathrm{CCl}_{4}$ injections. (a) Representative liver tissue sections from WT and CD154KO mice stained with the anti-F4/80 antigen monoclonal antibody after 3 and $9 \mathrm{CCl}_{4}$ injections (inj.). Top panels, low magnifications (scale bar $500 \mu \mathrm{m}$ ); bottom panels, high magnifications (scale bar $100 \mu \mathrm{m})(n=8$ for each condition in each group of mice). Relative liver levels of F4/80 (b), IL-4 (c), MCP-1 (d), IL-6 (e), and MIP-2 (f) mRNA (fold arbitrary units), in WT and CD154KO mice at time 0 and after 3 and 9 CCl injections (inj.) (mean $\pm \mathrm{SD},{ }^{*} p<0.05, n=8$ ).

noninfectious granuloma, the absence of CD154 is associated with an altered granulomatous inflammation progression.

CD154 may play a role in granulomatous inflammation by regulating macrophage functions. Indeed, macrophages are key immune cell effectors in granulomatous inflammation. Resident macrophages or macrophages derived from recruited monocytes are subjected to a range of signals at sites of granulomatous inflammation that activate them and induce differential functional programs. Macrophages are involved in virtually every step of granulomatous inflammation, orchestrating the proinflammatory granuloma microenvironment and being critical in fueling chronic inflammation and subsequent fibrosis $[3,5,10,12,13,76-78]$.

Macrophages express CD40, and the binding of CD154 activates monocytes/macrophages with essential consequences in tissue homeostasis by driving cytokine/chemokine, protease production and control of tissue clearance capacity, pathogen killing, or anti-tumor effects [51, 56, 58, 79-82]. The absence of CD154 is therefore likely to impact macrophage activation $[51,57]$. As there was a lack of evident 
1 week

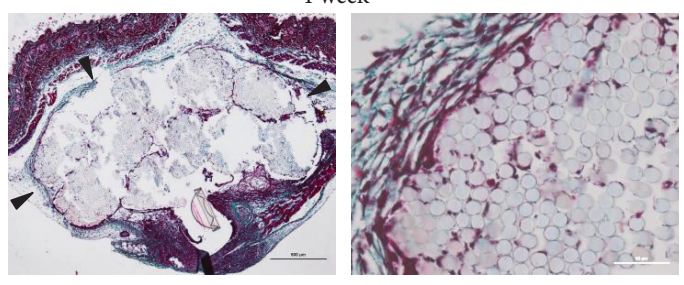

3 weeks

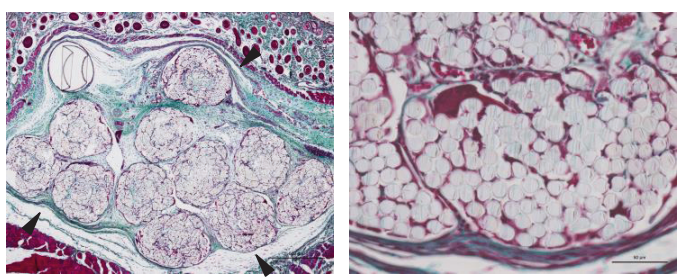

4 weeks

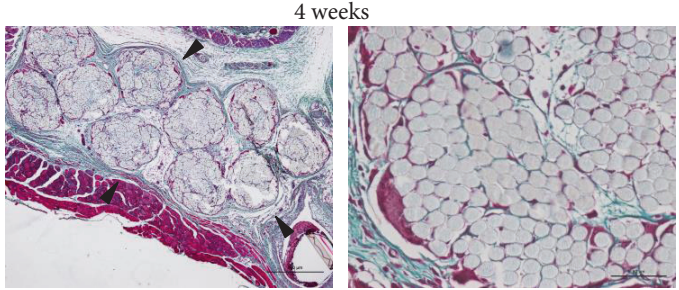

5 weeks
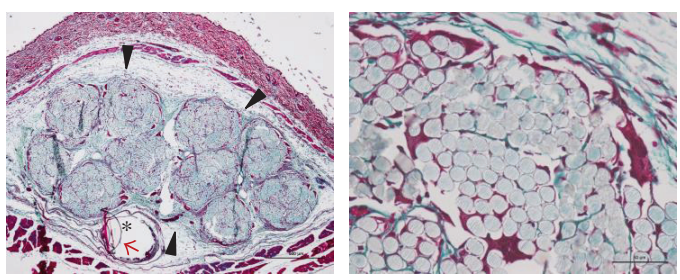

6 week

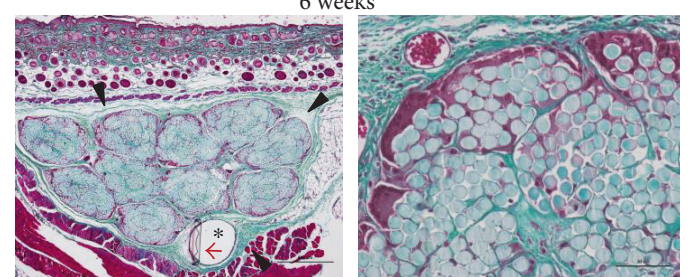

(a)
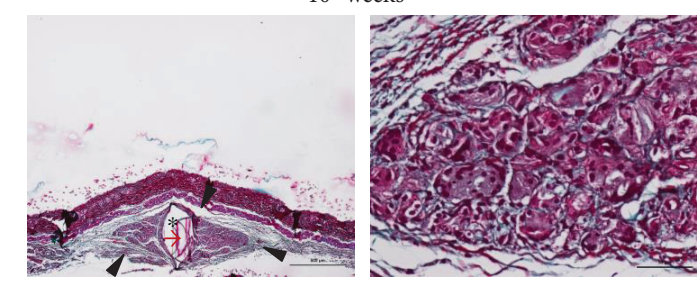

7 weeks

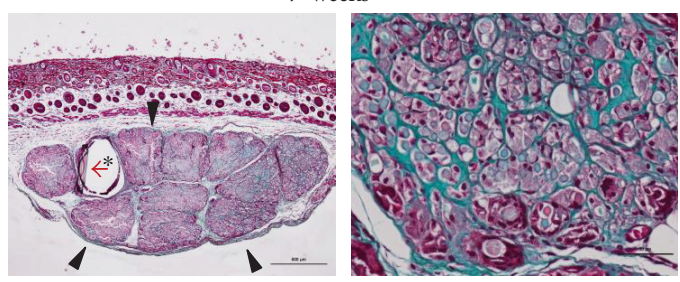

8 weeks

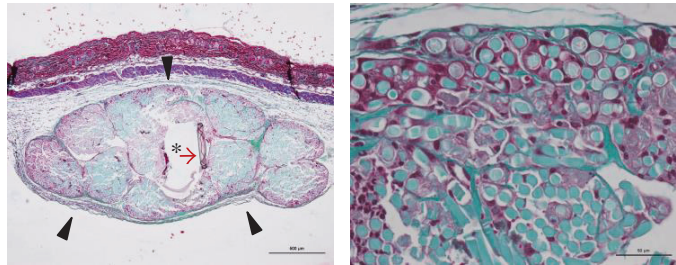

9 weeks

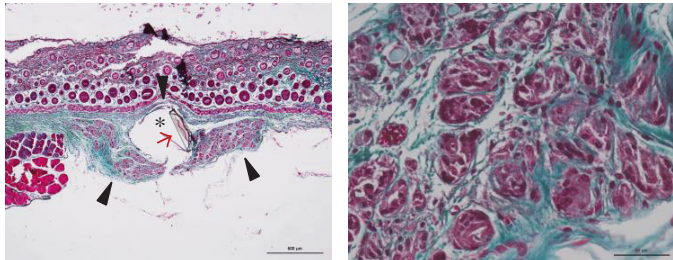

10 weeks

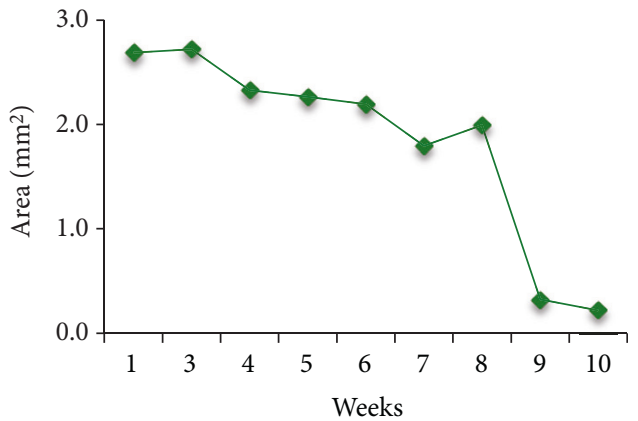

(b)

Figure 4: Absorbable suture bundles undergo a rapid bioresorption between weeks 8 and 10 postimplantation. (a) Tissue sections (low and high magnifications, scale bars 500 and $50 \mu \mathrm{m}$ for left and right panels, resp.) were obtained at week intervals and stained with Masson's trichrome. Microphotographs shown correspond to a representative kinetic of 3 experiments performed. Bundle contours showing rapid shrinking by week 8 are indicated by arrowheads. Red arrows indicate the nonabsorbable thread which, upon section by the microtome, creates an artefactual void on the tissue section (asterisk); (b) quantification of (a) suture bundle bioresorption. 
WT

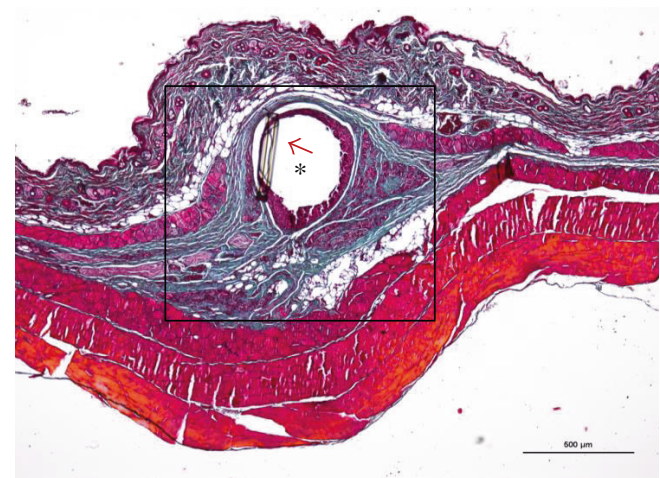

(a)

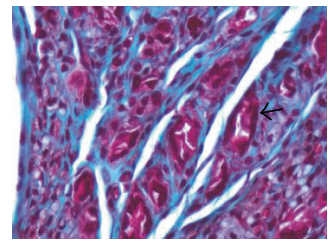

(b)

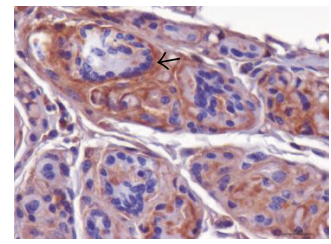

(c)
CD154KO

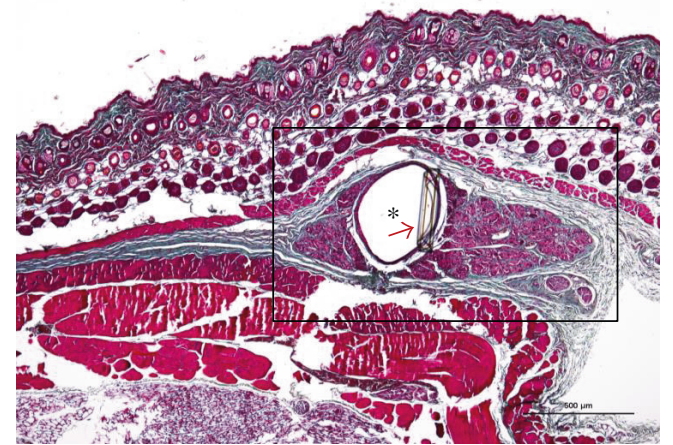

(d)

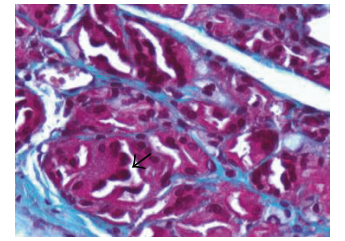

(e)

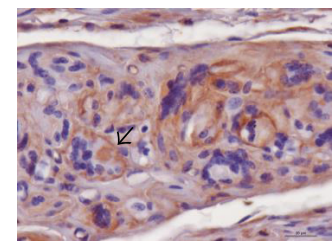

(f)

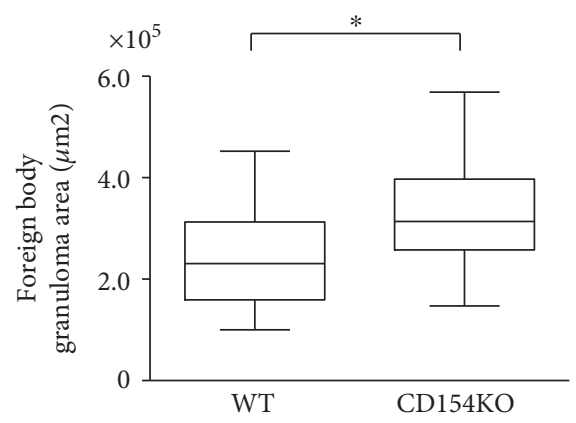

(g)

Figure 5: Differential clearance of suture bundles in WT and CD154KO mice. Representative Masson's trichrome-stained tissue sections from WT and CD154KO mice at week 10. (a and d) Low magnification (scale bar $500 \mu \mathrm{m}$ ); arrows indicate the nonresorbable thread which, upon section by the microtome, creates an artefactual void on the tissue section (asterisk); squares highlight the FBR in subcutaneous tissues. (b and e) High magnifications (scale bar $20 \mu \mathrm{m}$ ); the granulomas are composed of macrophages and multinucleated giant cells (MGCs) (arrows) bordered by fibrosis (green/blue). (c and f) Representative liver tissue sections from WT and CD154KO mice stained with the anti-F4/80 antigen monoclonal antibody at week 10; high magnifications (scale bar 20 $\mu \mathrm{m}$ ), macrophages, and MGCs (arrows) express the F4/80 antigen macrophagic marker. (g) Quantification of granuloma areas in WT and CD154KO mice $\left({ }^{*} p<0.05\right)$.

differences in the extent of the initial lesions, inflammatory cell recruitment, and extent of MGC generation, we hypothesize that the impaired clearance of the necrotic and calcified tissue and of suture bundles could be partly dependent on a phagocytosis defect. First, phagocytosis is an important mean through which macrophages contribute to tissue homeostasis, including the clearance of apoptotic/necrotic cells and damaged tissue components [83-85], and phagocytosis is regulated by the CD40 signaling ([86] and our study). Macrophage phagocytosis impairment is associated to delayed tissue repair $[87,88]$. Our results suggested that CD154 has a regulatory role on macrophage phagocytosis. Second, the absence of CD154 can be expected to reduce cytokine production by macrophages. Hence, CD154 deficiency, through the impairment of macrophage activation, may alter the transition towards the resolution of granulomatous inflammation. Indeed, the early stages of inflammation, including macrophage clearance of apoptotic cells, determine following resolution stages [1]. Macrophages are a heterogeneous population [89]. M1 macrophages mostly contribute to inflammation while M2 macrophages mostly contribute to tissue repair and remodeling. However, being not fully distinctive, CD40 is highly expressed on M1 macrophages relatively to M2 macrophages [90, 91]. Differently polarized macrophages coexist in FBR as shown for example by in situ studies [92]. Biomaterials have also been shown to induce a shift in M1/ M2 polarization dependent on the nature of the material $[78,93,94]$, and M1/M2 polarization may be linked to different outcome in granuloma progression [95, 96]. Macrophage polarization can be regulated by the $\mathrm{CD} 40$ signaling. For 


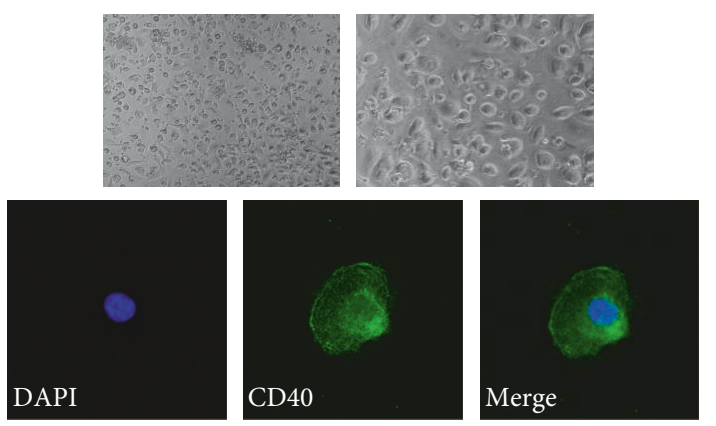

(a)

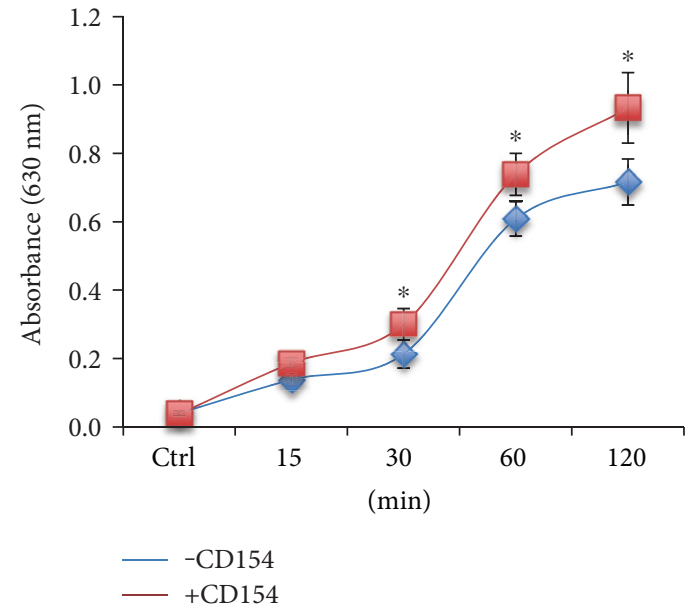

(c)

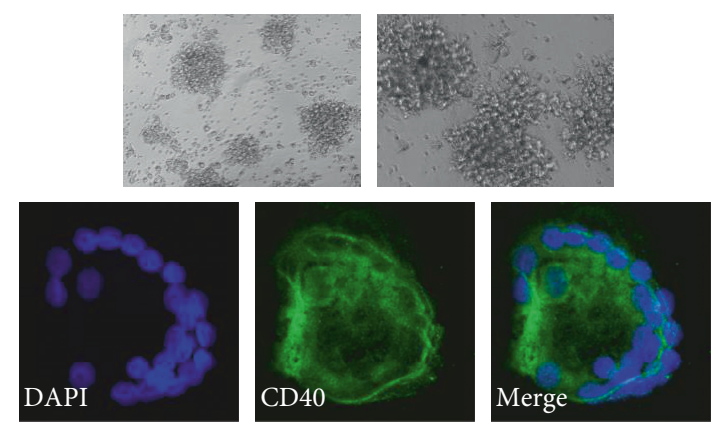

(b)

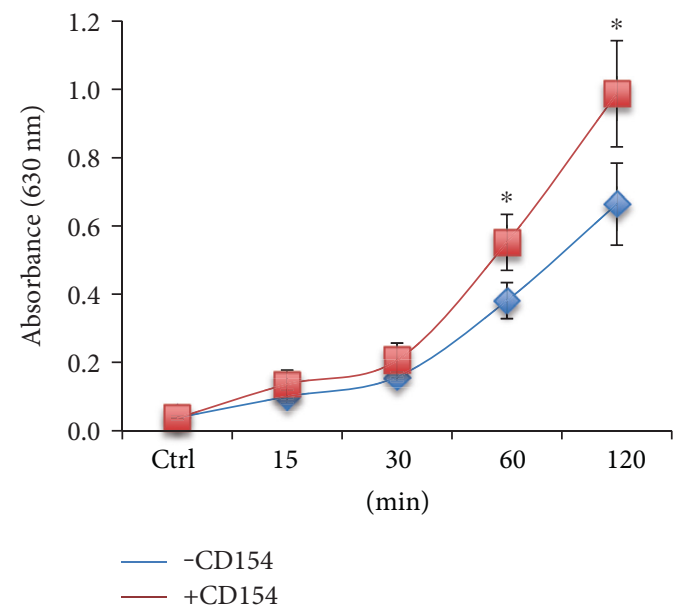

(d)

FIGURE 6: CD154 enhances phagocytosis by in vitro-derived macrophages. (a and b) CD40 is expressed by in vitro-derived macrophages and multinucleated giant cells (MGCs). (a) Macrophages derived from peripheral blood monocytes were immunostained for CD40 expression. Top panel, representative microphotographies of in vitro-derived macrophages $(\times 100$ and $\times 200$ magnifications); bottom panel, CD40 immunostaining; nuclei were counterstained with DAPI ( $\times 400$ magnification). (b) MGCs were obtained by IL-4-induced macrophage fusion and immunostained for CD40 expression. Top panel, representative microphotographies of in vitro-derived MGCs ( $\times 100$ and $\times 200$ magnifications); bottom panel, CD40 immunostaining; nuclei were counterstained with DAPI ( $\times 400$ magnification). (c and d) CD154 enhances phagocytosis by in vitro-derived macrophages. (c) Cultures of in vitro-derived macrophages were assayed for phagocytosis in the presence or not of rsCD154. (d) Results obtained after fusion induction by IL-4. Cells were prestimulated 24 hours with $200 \mathrm{ng} / \mathrm{mL}$ rsCD154, and phagocytosis of opsonized erythrocytes was measured at various time-points (mean $\pm \mathrm{SD}, n=6{ }^{*} p<0.05$ ).

example, IFN- $\gamma$ in combination with CD154 can switch M2 to M1-like macrophages $[97,98]$ and macrophages of mice deficient in CD40-TRAF6 signaling show a polarization towards a M2 signature [99]. However, macrophages present in the FBR may not always fit with the classical M1/M2 phenotype signature [100] and the assignment of macrophages to a particular M1 or M2 lineage in granulomatous inflammation remains an open question needing studies of dynamic changes in macrophage phenotype transition in the progression of granulomatous inflammation. The role of CD154 in M1/M2 transition and how this could affect progression of granulomatous inflammation therefore remains to be analyzed.

The role of CD154 on functional properties of MGCs will require experiments with purified MGC populations. Apart from their role on the degradation/resorption of the foreign material [101], MGCs are thought to be instrumental in the phagocytic clearance of foreign material but little is known about the magnitude of their contribution and how this function is regulated. Indeed, human MGCs derived from cultured macrophages have phagocytic properties [75]. MGCs are also the source of inflammatory mediators and interestingly adapt the pattern of inflammatory mediators they produce depending on the nature of the foreign material they encounter [102].

Control of macrophage activation by CD154 does not exclude other potential mechanisms for the altered granulomatous inflammation in the absence of CD154. Additional mechanisms may be related to the regulation of the global cytokine network by CD154, as, in addition to macrophages, CD154 is a general cytokine/chemokine inducer for a variety of cells. Various cytokine deficiencies are indeed associated to altered granuloma progression [14, 103]. The absence of CD154 is likely to alter the cytokine network in the granuloma milieu. Among cytokine expression that we studied in the liver injury model, MIP-2 was found to be downregulated; MIP-2 is produced by a variety of cells, including macrophages, in response to injury and is an important 
mediator of inflammation in acute liver injury [104]. The downregulation of MIP-2 expression in CD154-deficient mice suggests potential involvement of MIP-2 in the progression of granuloma inflammation.

Another point of discussion is the source of CD154 during the progression of granulomatous inflammation. Activated platelets are a major source of CD154 in the organism. Together with macrophages and other inflammatory cells, platelets are immediately available and activated at sites of tissue injury and likely to play an important role in providing inflammatory mediators, including CD154. Platelets are important players in the immune system. Platelet-associated and soluble CD154 are important contributors to the inflammatory reaction $[45,46]$, and the role of platelets in initiating, sustaining, and resolving inflammation is increasingly stressed [37]. It is tempting to speculate that they contribute to the natural history of granulomatous inflammation. However, potential other sources of CD154 exist, as various cells, including $\mathrm{CD}^{+} \mathrm{T}$ cells and fibroblasts, that are important cell components and functional players in granuloma progression [105]. In inflammatory conditions, these cells can both express CD154 at their surface and release a soluble form. Therefore, the granuloma inflammatory milieu is likely to be a source of CD154. Apart from mechanisms underlying CD154 contribution, the control of the foreign body reaction in order to slow or prevent the formation of a fibrotic capsule remains a major challenge in the field of biomaterial research. The responsibility of macrophages in the fibrotic process is well established, and the CD40/CD154 dyad may represent a potential target to delay fibrotic encapsulation of implanted materials. Altogether, our study suggests that CD154 contributes to the natural history of granulomatous inflammation.

\section{Conflicts of Interest}

The authors declare no conflict of interest regarding the publication of this paper.

\section{Acknowledgments}

Julien Villeneuve acknowledges support from a Marie Curie International Outgoing Fellowship within the 7th European Community Framework Program.

\section{References}

[1] C. N. Serhan and J. Savill, "Resolution of inflammation: the beginning programs the end," Nature Immunology, vol. 6, no. 12, pp. 1191-1197, 2005.

[2] C. Nathan and A. Ding, "Nonresolving inflammation," Cell, vol. 140 , no. 6, pp. 871-882, 2010.

[3] D. O. Adams, "The granulomatous inflammatory response. A review," The American Journal of Pathology, vol. 84, no. 1, pp. 164-192, 1976.

[4] G. T. Williams and W. J. Williams, "Granulomatous inflammation-a review," Journal of Clinical Pathology, vol. 36, no. 7, pp. 723-733, 1983.
[5] W. L. Epstein and K. Fukuyama, "Mechanisms of granulomatous inflammation," Immunology Series, vol. 46, pp. 687-721, 1989.

[6] A. Zumla and D. G. James, "Granulomatous infections: etiology and classification," Clinical Infectious Diseases, vol. 23, no. 1, pp. 146-158, 1996.

[7] J. M. Anderson, "Multinucleated giant cells," Current Opinion in Hematology, vol. 7, no. 1, pp. 40-47, 2000.

[8] M. C. Sneller, "Granuloma formation, implications for the pathogenesis of vasculitis," Cleveland Clinic Journal of Medicine, vol. 69, Supplement 2, pp. SII40-SII43, 2002.

[9] C. J. Wilson, R. E. Clegg, D. I. Leavesley, and M. J. Pearcy, "Mediation of biomaterial-cell interactions by adsorbed proteins: a review," Tissue Engineering, vol. 11, no. 1-2, pp. 1-18, 2005.

[10] D. T. Luttikhuizen, M. C. Harmsen, and M. J. Van Luyn, "Cellular and molecular dynamics in the foreign body reaction," Tissue Engineering, vol. 12, no. 7, pp. 19551970, 2006.

[11] Z. Xia and J. T. Triffitt, "A review on macrophage responses to biomaterials," Biomedical Materials, vol. 1, no. 1, pp. R1R9, 2006.

[12] J. M. Anderson, A. Rodriguez, and D. T. Chang, "Foreign body reaction to biomaterials," Seminars in Immunology, vol. 20, no. 2, pp. 86-100, 2008.

[13] S. Franz, S. Rammelt, D. Scharnweber, and J. C. Simon, "Immune responses to implants - a review of the implications for the design of immunomodulatory biomaterials," Biomaterials, vol. 32, no. 28, pp. 6692-6709, 2011.

[14] H. J. Petersen and A. M. Smith, "The role of the innate immune system in granulomatous disorders," Frontiers in Immunology, vol. 4, p. 120, 2013.

[15] C. D. Rose, B. Neven, and C. Wouters, "Granulomatous inflammation: the overlap of immune deficiency and inflammation," Best Practice \& Research. Clinical Rheumatology, vol. 28, no. 2, pp. 191-212, 2014.

[16] T. J. Chambers, "Multinucleate giant cells," The Journal of Pathology, vol. 126, no. 3, pp. 125-148, 1978.

[17] A. Vignery, "Macrophage fusion: the making of osteoclasts and giant cells," The Journal of Experimental Medicine, vol. 202, no. 3, pp. 337-340, 2005.

[18] S. L. Kunkel, S. W. Chensue, R. M. Strieter, J. P. Lynch, and D. G. Remick, "Cellular and molecular aspects of granulomatous inflammation," American Journal of Respiratory Cell and Molecular Biology, vol. 1, no. 6, pp. 439-447, 1989.

[19] S. Fais, V. L. Burgio, M. Silvestri, M. R. Capobianchi, A. Pacchiarotti, and F. Pallone, "Multinucleated giant cells generation induced by interferon-gamma. Changes in the expression and distribution of the intercellular adhesion molecule-1 during macrophages fusion and multinucleated giant cell formation," Laboratory Investigation, vol. 71, no. 5, pp. 737-744, 1994.

[20] A. K. McNally and J. M. Anderson, "Interleukin-4 induces foreign body giant cells from human monocytes/macrophages. Differential lymphokine regulation of macrophage fusion leads to morphological variants of multinucleated giant cells," The American Journal of Pathology, vol. 147, no. 5, pp. 1487-1499, 1995.

[21] K. M. DeFife, C. R. Jenney, A. K. McNally, E. Colton, and J. M. Anderson, "Interleukin-13 induces human monocyte/ macrophage fusion and macrophage mannose receptor 
expression," Journal of Immunology, vol. 158, no. 7, pp. 3385-3390, 1997.

[22] J. L. Flynn and J. Chan, "Immunology of tuberculosis," Annual Review of Immunology, vol. 19, pp. 93-129, 2001.

[23] T. R. Kyriakides and P. Bornstein, "Matricellular proteins as modulators of wound healing and the foreign body response," Thrombosis and Haemostasis, vol. 90, no. 6, pp. 986-992, 2003.

[24] A. T. Tsai, J. Rice, M. Scatena, L. Liaw, B. D. Ratner, and C. M. Giachelli, "The role of osteopontin in foreign body giant cell formation,” Biomaterials, vol. 26, no. 29, pp. 5835-5843, 2005.

[25] L. Helming and S. Gordon, "The molecular basis of macrophage fusion," Immunobiology, vol. 212, no. 9-10, pp. 785-793, 2007.

[26] B. G. Keselowsky, A. W. Bridges, K. L. Burns et al., "Role of plasma fibronectin in the foreign body response to biomaterials," Biomaterials, vol. 28, no. 25, pp. 3626-3631, 2007.

[27] A. K. McNally, J. A. Jones, S. R. Macewan, E. Colton, and J. M. Anderson, "Vitronectin is a critical protein adhesion substrate for IL-4-induced foreign body giant cell formation," Journal of Biomedical Materials Research. Part a, vol. 86, no. 2, pp. 535-543, 2008.

[28] S. MacLauchlan, E. A. Skokos, N. Meznarich et al., "Macrophage fusion, giant cell formation, and the foreign body response require matrix metalloproteinase 9," Journal of Leukocyte Biology, vol. 85, no. 4, pp. 617-626, 2009.

[29] T. R. Kyriakides, K. J. Leach, A. S. Hoffman, B. D. Ratner, and P. Bornstein, "Mice that lack the angiogenesis inhibitor, thrombospondin 2, mount an altered foreign body reaction characterized by increased vascularity," Proceedings of the National Academy of Sciences of the United States of America, vol. 96, no. 8, pp. 4449-4454, 1999.

[30] A. Solowiej, P. Biswas, D. Graesser, and J. A. Madri, "Lack of platelet endothelial cell adhesion molecule-1 attenuates foreign body inflammation because of decreased angiogenesis," The American Journal of Pathology, vol. 162, no. 3, pp. 953962, 2003.

[31] R. J. Schutte, A. Parisi-Amon, and W. M. Reichert, "Cytokine profiling using monocytes/macrophages cultured on common biomaterials with a range of surface chemistries," Journal of Biomedical Materials Research. Part A, vol. 88, no. 1, pp. 128139, 2009.

[32] S. Ghanaati, M. Barbeck, C. Orth et al., "Influence of betatricalcium phosphate granule size and morphology on tissue reaction in vivo," Acta Biomaterialia, vol. 6, no. 12, pp. 4476-4487, 2010.

[33] J. M. Morais, F. Papadimitrakopoulos, and D. J. Burgess, "Biomaterials/tissue interactions: possible solutions to overcome foreign body response," The AAPS Journal, vol. 12, no. 2, pp. 188-196, 2010.

[34] S. Ghanaati, M. Schlee, M. J. Webber et al., "Evaluation of the tissue reaction to a new bilayered collagen matrix in vivo and its translation to the clinic," Biomedical Materials, vol. 6, no. 1 , article $015010,2011$.

[35] A. K. Blakney, M. D. Swartzlander, and S. J. Bryant, "The effects of substrate stiffness on the in vitro activation of macrophages and in vivo host response to poly(ethylene glycol)-based hydrogels," Journal of Biomedical Materials Research. Part A, vol. 100, no. 6, pp. 1375-1386, 2012.
[36] J. D. Bryers, C. M. Giachelli, and B. D. Ratner, "Engineering biomaterials to integrate and heal: the biocompatibility paradigm shifts," Biotechnology and Bioengineering, vol. 109, no. 8, pp. 1898-1911, 2012.

[37] J. W. Semple and J. Freedman, "Platelets and innate immunity," Cellular and Molecular Life Sciences, vol. 67, no. 4, pp. 499-511, 2010.

[38] A. T. Nurden, P. Nurden, M. Sanchez, I. Andia, and E. Anitua, "Platelets and wound healing," Frontiers in Bioscience, vol. 13, pp. 3532-3548, 2008.

[39] A. Vieira-de-Abreu, R. A. Campbell, A. S. Weyrich, and G. A. Zimmerman, "Platelets: versatile effector cells in hemostasis, inflammation, and the immune continuum," Seminars in Immunopathology, vol. 34, no. 1, pp. 5-30, 2012.

[40] A. Dewitte, A. Tanga, J. Villeneuve et al., "New frontiers for platelet CD154," Experimental Hematology \& Oncology, vol. 4, p. 6, 2015.

[41] M. R. Thomas and R. F. Storey, "The role of platelets in inflammation," Thrombosis and Haemostasis, vol. 114, no. 3, pp. 449-458, 2015.

[42] I. Del Conde, M. A. Cruz, H. Zhang, J. A. Lopez, and V. Afshar-Kharghan, "Platelet activation leads to activation and propagation of the complement system," The Journal of Experimental Medicine, vol. 201, no. 6, pp. 871-879, 2005.

[43] L. Tang and J. W. Eaton, "Natural responses to unnatural materials: a molecular mechanism for foreign body reactions," Molecular Medicine, vol. 5, no. 6, pp. 351-358, 1999.

[44] M. B. Gorbet and M. V. Sefton, "Biomaterial-associated thrombosis: roles of coagulation factors, complement, platelets and leukocytes," Biomaterials, vol. 25, no. 26, pp. 5681-5703, 2004.

[45] C. van Kooten and J. Banchereau, "CD40-CD40 ligand," Journal of Leukocyte Biology, vol. 67, no. 1, pp. 2-17, 2000.

[46] U. Schonbeck and P. Libby, "The CD40/CD154 receptor/ ligand dyad," Cellular and Molecular Life Sciences, vol. 58, no. 1, pp. 4-43, 2001.

[47] S. Lepreux, J. Villeneuve, A. Dewitte, A. M. Berard, A. Desmouliere, and J. Ripoche, "CD40 signaling and hepatic steatosis: unanticipated links," Clinics and Research in Hepatology and Gastroenterology, vol. 16, 2016.

[48] S. X. Anand, J. F. Viles-Gonzalez, J. J. Badimon, E. Cavusoglu, and J. D. Marmur, "Membrane-associated CD40L and sCD40L in atherothrombotic disease," Thrombosis and Haemostasis, vol. 90, no. 3, pp. 377-384, 2003.

[49] M. R. Alderson, R. J. Armitage, T. W. Tough, L. Strockbine, W. C. Fanslow, and M. K. Spriggs, "CD40 expression by human monocytes: regulation by cytokines and activation of monocytes by the ligand for CD40," The Journal of Experimental Medicine, vol. 178, no. 2, pp. 669-674, 1993.

[50] D. H. Wagner Jr., R. D. Stout, and J. Suttles, "Role of the CD40-CD40 ligand interaction in CD4+ T cell contactdependent activation of monocyte interleukin-1 synthesis," European Journal of Immunology, vol. 24, no. 12, pp. 31483154, 1994.

[51] R. D. Stout and J. Suttles, "The many roles of CD40 in cellmediated inflammatory responses," Immunology Today, vol. 17, no. 10, pp. 487-492, 1996.

[52] J. Suttles and R. D. Stout, "Macrophage CD40 signaling: a pivotal regulator of disease protection and pathogenesis," Seminars in Immunology, vol. 21, no. 5, pp. 257-264, 2009. 
[53] V. Henn, J. R. Slupsky, M. Grafe et al., "CD40 ligand on activated platelets triggers an inflammatory reaction of endothelial cells," Nature, vol. 391, no. 6667, pp. 591594, 1998.

[54] P. Andre, L. Nannizzi-Alaimo, S. K. Prasad, and D. R. Phillips, "Platelet-derived CD40L: the switch-hitting player of cardiovascular disease," Circulation, vol. 106, no. 8, pp. 896-899, 2002.

[55] J. F. Viallard, A. Solanilla, B. Gauthier et al., "Increased soluble and platelet-associated CD40 ligand in essential thrombocythemia and reactive thrombocytosis," Blood, vol. 99, no. 7, pp. 2612-2614, 2002.

[56] N. Malik, B. W. Greenfield, A. F. Wahl, and P. A. Kiener, "Activation of human monocytes through CD40 induces matrix metalloproteinases," Journal of Immunology, vol. 156, no. 10, pp. 3952-3960, 1996.

[57] R. D. Stout, J. Suttles, J. Xu, I. S. Grewal, and R. A. Flavell, "Impaired T cell-mediated macrophage activation in CD40 ligand-deficient mice," Journal of Immunology, vol. 156, no. 1, pp. 8-11, 1996.

[58] F. Mach, U. Schonbeck, J. Y. Bonnefoy, J. S. Pober, and P. Libby, "Activation of monocyte/macrophage functions related to acute atheroma complication by ligation of CD40: induction of collagenase, stromelysin, and tissue factor," Circulation, vol. 96, no. 2, pp. 396-399, 1997.

[59] I. S. Grewal and R. A. Flavell, "CD40 and CD154 in cellmediated immunity," Annual Review of Immunology, vol. 16, pp. 111-135, 1998.

[60] A. Miga, S. Masters, M. Gonzalez, and R. J. Noelle, "The role of CD40-CD154 interactions in the regulation of cell mediated immunity," Immunological Investigations, vol. 29, no. 2, pp. 111-114, 2000.

[61] L. Wu, J. Fan, S. Matsumoto, and T. Watanabe, "Induction and regulation of matrix metalloproteinase- 12 by cytokines and CD40 signaling in monocyte/macrophages," Biochemical and Biophysical Research Communications, vol. 269, no. 3, pp. 808-815, 2000.

[62] U. Schonbeck and P. Libby, "CD40 signaling and plaque instability," Circulation Research, vol. 89, no. 12, pp. 10921103, 2001.

[63] A. J. Chase, M. Bond, M. F. Crook, and A. C. Newby, "Role of nuclear factor-kappa B activation in metalloproteinase-1, -3, and -9 secretion by human macrophages in vitro and rabbit foam cells produced in vivo," Arteriosclerosis, Thrombosis, and Vascular Biology, vol. 22, no. 5, pp. 765-771, 2002.

[64] A. C. Newby, "Metalloproteinase expression in monocytes and macrophages and its relationship to atherosclerotic plaque instability," Arteriosclerosis, Thrombosis, and Vascular Biology, vol. 28, no. 12, pp. 2108-2114, 2008.

[65] D. Lorena, I. A. Darby, A. P. Gadeau et al., "Osteopontin expression in normal and fibrotic liver. Altered liver healing in osteopontin-deficient mice," Journal of Hepatology, vol. 44, no. 2, pp. 383-390, 2006.

[66] J. Conn Jr., R. Oyasu, M. Welsh, and J. M. Beal, "Vicryl (polyglactin 910) synthetic absorbable sutures," American Journal of Surgery, vol. 128, no. 1, pp. 19-23, 1974.

[67] C. G. Munton, C. I. Phillips, B. Martin, R. S. Bartholomew, and I. Capperauld, "Vicryl (Polyglactin 910): a new synthetic absorbable suture in ophthalmic surgery. A preliminary study," The British Journal of Ophthalmology, vol. 58, no. 11, pp. 941-947, 1974.
[68] P. H. Craig, J. A. Williams, K. W. Davis et al., "A biologic comparison of polyglactin 910 and polyglycolic acid synthetic absorbable sutures," Surgery, Gynecology \& Obstetrics, vol. 141, no. 1, pp. 1-10, 1975.

[69] C. Dugast, A. Gaudin, and L. Toujas, "Generation of multinucleated giant cells by culture of monocyte-derived macrophages with IL-4," Journal of Leukocyte Biology, vol. 61, no. 4, pp. 517-521, 1997.

[70] J. Villeneuve, S. Lepreux, A. Mulot et al., "A protective role for CD154 in hepatic steatosis in mice," Hepatology, vol. 52, no. 6, pp. 1968-1979, 2010.

[71] C. G. Huh, V. M. Factor, A. Sanchez, K. Uchida, E. A. Conner, and S. S. Thorgeirsson, "Hepatocyte growth factor/c-met signaling pathway is required for efficient liver regeneration and repair," Proceedings of the National Academy of Sciences of the United States of America, vol. 101, no. 13, pp. 44774482, 2004.

[72] J. A. Bezerra, T. H. Bugge, H. Melin-Aldana et al., "Plasminogen deficiency leads to impaired remodeling after a toxic injury to the liver," Proceedings of the National Academy of Sciences of the United States of America, vol. 96, no. 26, pp. 15143-15148, 1999.

[73] J. A. Bezerra, A. R. Currier, H. Melin-Aldana et al., "Plasminogen activators direct reorganization of the liver lobule after acute injury," The American Journal of Pathology, vol. 158, no. 3, pp. 921-929, 2001.

[74] M. Vert, "Degradable and bioresorbable polymers in surgery and in pharmacology: beliefs and facts," Journal of Materials Science. Materials in Medicine, vol. 20, no. 2, pp. 437-446, 2009.

[75] L. Schlesinger, R. A. Musson, and R. B. Johnston Jr., "Functional and biochemical studies of multinucleated giant cells derived from the culture of human monocytes," The Journal of Experimental Medicine, vol. 159, no. 4, pp. 1289-1294, 1984.

[76] W. Kenneth Ward, "A review of the foreign-body response to subcutaneously-implanted devices: the role of macrophages and cytokines in biofouling and fibrosis," Journal of Diabetes Science and Technology, vol. 2, no. 5, pp. 768-777, 2008.

[77] B. N. Brown, B. D. Ratner, S. B. Goodman, S. Amar, and S. F. Badylak, "Macrophage polarization: an opportunity for improved outcomes in biomaterials and regenerative medicine," Biomaterials, vol. 33, no. 15, pp. 3792-3802, 2012.

[78] J. Kzhyshkowska, A. Gudima, V. Riabov, C. Dollinger, P. Lavalle, and N. E. Vrana, "Macrophage responses to implants: prospects for personalized medicine," Journal of Leukocyte Biology, vol. 98, no. 6, pp. 953-962, 2015.

[79] T. Hayashi, S. P. Rao, P. R. Meylan, R. S. Kornbluth, and A. Catanzaro, "Role of CD40 ligand in Mycobacterium avium infection," Infection and Immunity, vol. 67, no. 7, pp. 35583565, 1999.

[80] J. Ma, T. Chen, J. Mandelin et al., "Regulation of macrophage activation," Cellular and Molecular Life Sciences, vol. 60, no. 11, pp. 2334-2346, 2003.

[81] C. S. Subauste, "Autophagy in immunity against Toxoplasma gondii," Current Topics in Microbiology and Immunology, vol. 335, pp. 251-265, 2009.

[82] A. L. Rakhmilevich, K. L. Alderson, and P. M. Sondel, "T-cell-independent antitumor effects of CD40 ligation," International Reviews of Immunology, vol. 31, no. 4, pp. 267-278, 2012. 
[83] T. J. Koh and L. A. DiPietro, "Inflammation and wound healing: the role of the macrophage," Expert Reviews in Molecular Medicine, vol. 13, article e23, 2011.

[84] P. J. Murray and T. A. Wynn, "Protective and pathogenic functions of macrophage subsets," Nature Reviews. Immunology, vol. 11, no. 11, pp. 723-737, 2011.

[85] S. J. Van Dyken and R. M. Locksley, "Interleukin-4- and interleukin-13-mediated alternatively activated macrophages: roles in homeostasis and disease," Annual Review of Immunology, vol. 31, pp. 317-343, 2013.

[86] M. J. Scott, J. J. Hoth, M. K. Stagner, S. A. Gardner, J. C. Peyton, and W. G. Cheadle, "CD40-CD154 interactions between macrophages and natural killer cells during sepsis are critical for macrophage activation and are not interferon gamma dependent," Clinical and Experimental Immunology, vol. 137, no. 3, pp. 469-477, 2004.

[87] M. E. Swift, A. L. Burns, K. L. Gray, and L. A. DiPietro, “Agerelated alterations in the inflammatory response to dermal injury," The Journal of Investigative Dermatology, vol. 117, no. 5, pp. 1027-1035, 2001.

[88] S. Khanna, S. Biswas, Y. Shang et al., "Macrophage dysfunction impairs resolution of inflammation in the wounds of diabetic mice," PloS One, vol. 5, no. 3, article e9539, 2010.

[89] S. Gordon and P. R. Taylor, "Monocyte and macrophage heterogeneity," Nature Reviews. Immunology, vol. 5, no. 12, pp. 953-964, 2005.

[90] J. E. Glim, F. B. Niessen, V. Everts, M. van Egmond, and R. H. Beelen, "Platelet derived growth factor-CC secreted by M2 macrophages induces alpha-smooth muscle actin expression by dermal and gingival fibroblasts," Immunobiology, vol. 218, no. 6, pp. 924-929, 2013.

[91] D. Y. Vogel, J. E. Glim, A. W. Stavenuiter et al., "Human macrophage polarization in vitro: maturation and activation methods compared," Immunobiology, vol. 219, no. 9, pp. 695-703, 2014.

[92] M. H. Barros, F. Hauck, J. H. Dreyer, B. Kempkes, and G. Niedobitek, "Macrophage polarisation: an immunohistochemical approach for identifying M1 and M2 macrophages," PloS One, vol. 8, no. 11, article e80908, 2013.

[93] N. Grotenhuis, Y. Bayon, J. F. Lange, G. J. Van Osch, and Y. M. Bastiaansen-Jenniskens, "A culture model to analyze the acute biomaterial-dependent reaction of human primary macrophages," Biochemical and Biophysical Research Communications, vol. 433, no. 1, pp. 115-120, 2013.

[94] G. S. Boersema, N. Grotenhuis, Y. Bayon, J. F. Lange, and Y. M. Bastiaansen-Jenniskens, "The effect of biomaterials used for tissue regeneration purposes on polarization of macrophages," BioResearch Open Access, vol. 5, no. 1, pp. 6-14, 2016.

[95] Z. Huang, Q. Luo, Y. Guo et al., "Mycobacterium tuberculosis-induced polarization of human macrophage orchestrates the formation and development of tuberculous granulomas in vitro," PloS One, vol. 10, no. 6, article e0129744, 2015.

[96] J. Asai, "What is new in the histogenesis of granulomatous skin diseases?" The Journal of Dermatology, vol. 44, no. 3, pp. 297-303, 2017.

[97] M. Heusinkveld, P. J. de Vos van Steenwijk, R. Goedemans et al., "M2 macrophages induced by prostaglandin E2 and IL-6 from cervical carcinoma are switched to activated M1 macrophages by CD4+ Th1 cells," Journal of Immunology, vol. 187, no. 3, pp. 1157-1165, 2011.

[98] N. Luheshi, G. Davies, and J. Legg, "Understanding the influence of the tumor microenvironment on macrophage responses to CD40 agonists," Oncoimmunology, vol. 3, no. 1, article e27615, 2014.

[99] E. Lutgens, D. Lievens, L. Beckers et al., "Deficient CD40TRAF6 signaling in leukocytes prevents atherosclerosis by skewing the immune response toward an antiinflammatory profile," The Journal of Experimental Medicine, vol. 207, no. 2, pp. 391-404, 2010.

[100] S. M. van Putten, D. T. Ploeger, E. R. Popa, and R. A. Bank, "Macrophage phenotypes in the collagen-induced foreign body reaction in rats," Acta Biomaterialia, vol. 9, no. 5, pp. 6502-6510, 2013.

[101] W. G. Brodbeck and J. M. Anderson, "Giant cell formation and function," Current Opinion in Hematology, vol. 16, no. 1, pp. 53-57, 2009.

[102] D. T. Luttikhuizen, P. Y. Dankers, M. C. Harmsen, and M. J. van Luyn, "Material dependent differences in inflammatory gene expression by giant cells during the foreign body reaction," Journal of Biomedical Materials Research. Part A, vol. 83, no. 3, pp. 879-886, 2007.

[103] L. Ramakrishnan, "Revisiting the role of the granuloma in tuberculosis," Nature Reviews. Immunology, vol. 12, no. 5, pp. 352-366, 2012.

[104] C. C. Qin, Y. N. Liu, Y. Hu, Y. Yang, and Z. Chen, "Macrophage inflammatory protein-2 as mediator of inflammation in acute liver injury," World Journal of Gastroenterology, vol. 23, no. 17, pp. 3043-3052, 2017.

[105] M. Hilhorst, T. Shirai, G. Berry, J. J. Goronzy, and C. M. Weyand, "T cell-macrophage interactions and granuloma formation in vasculitis," Frontiers in Immunology, vol. 5, p. $432,2014$. 


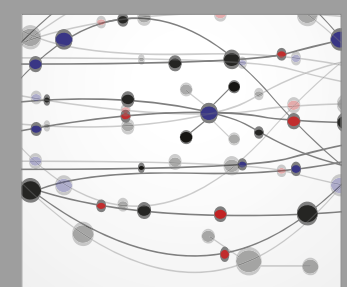

The Scientific World Journal
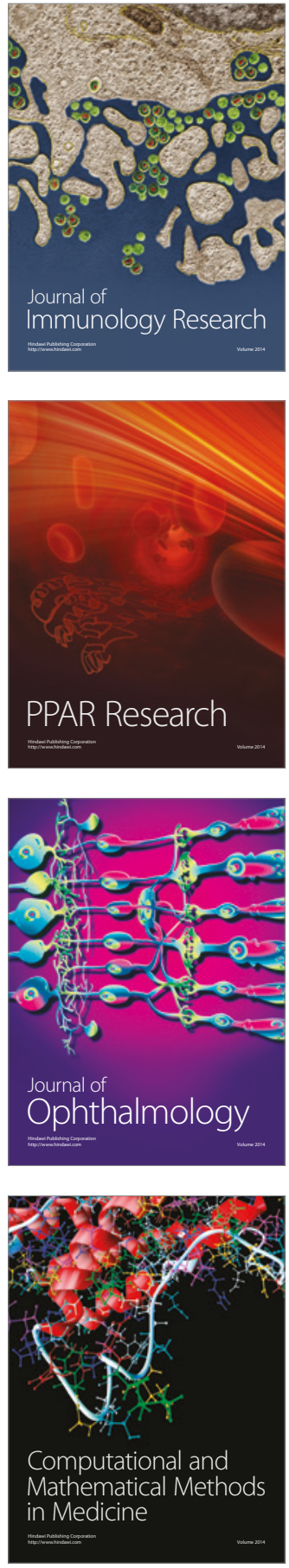

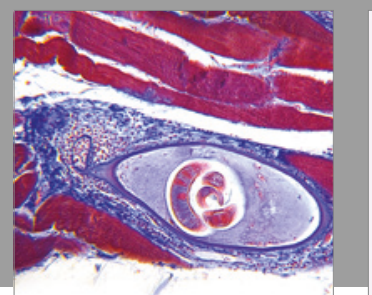

Gastroenterology Research and Practice
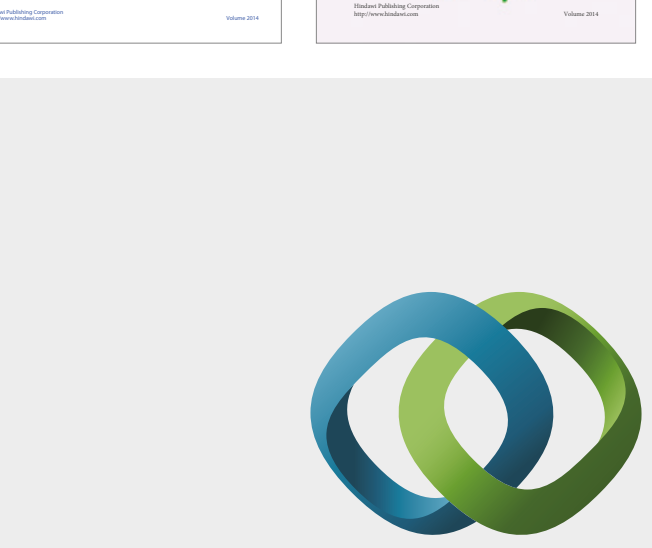

\section{Hindawi}

Submit your manuscripts at

https://www.hindawi.com
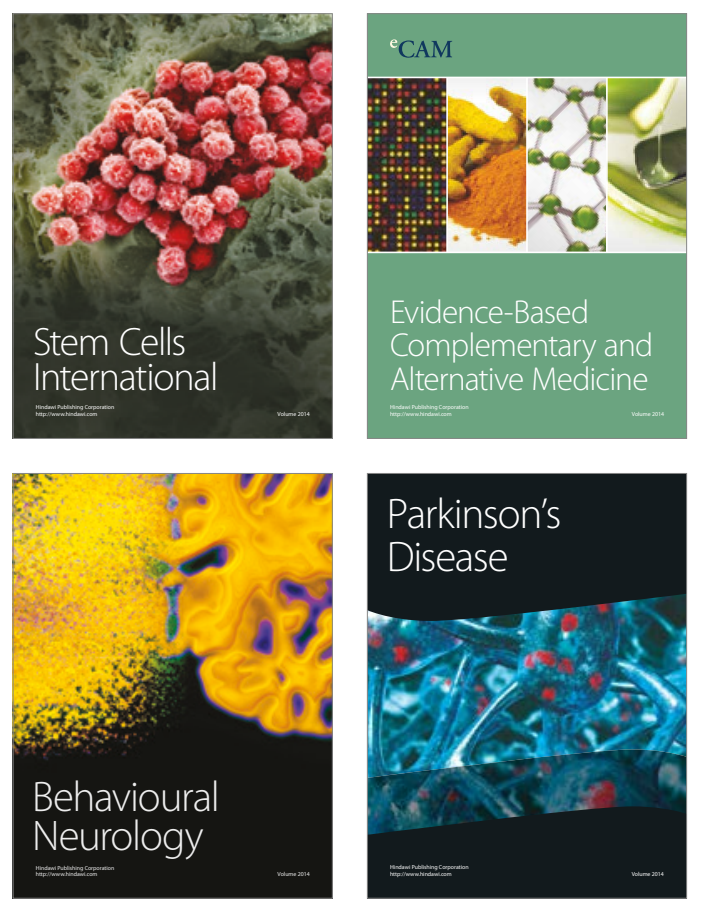
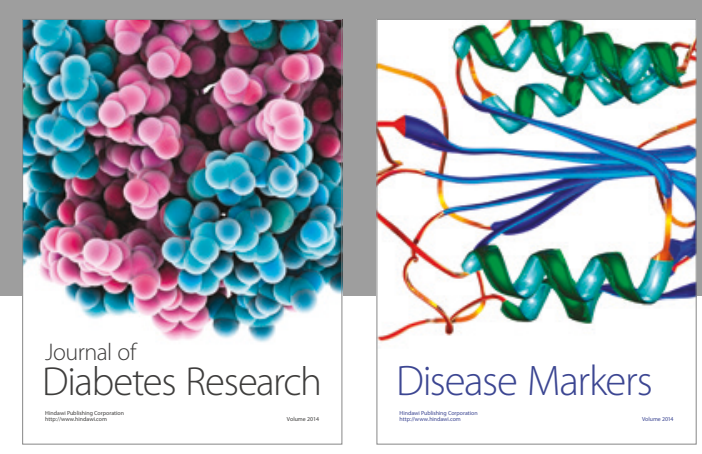

Disease Markers
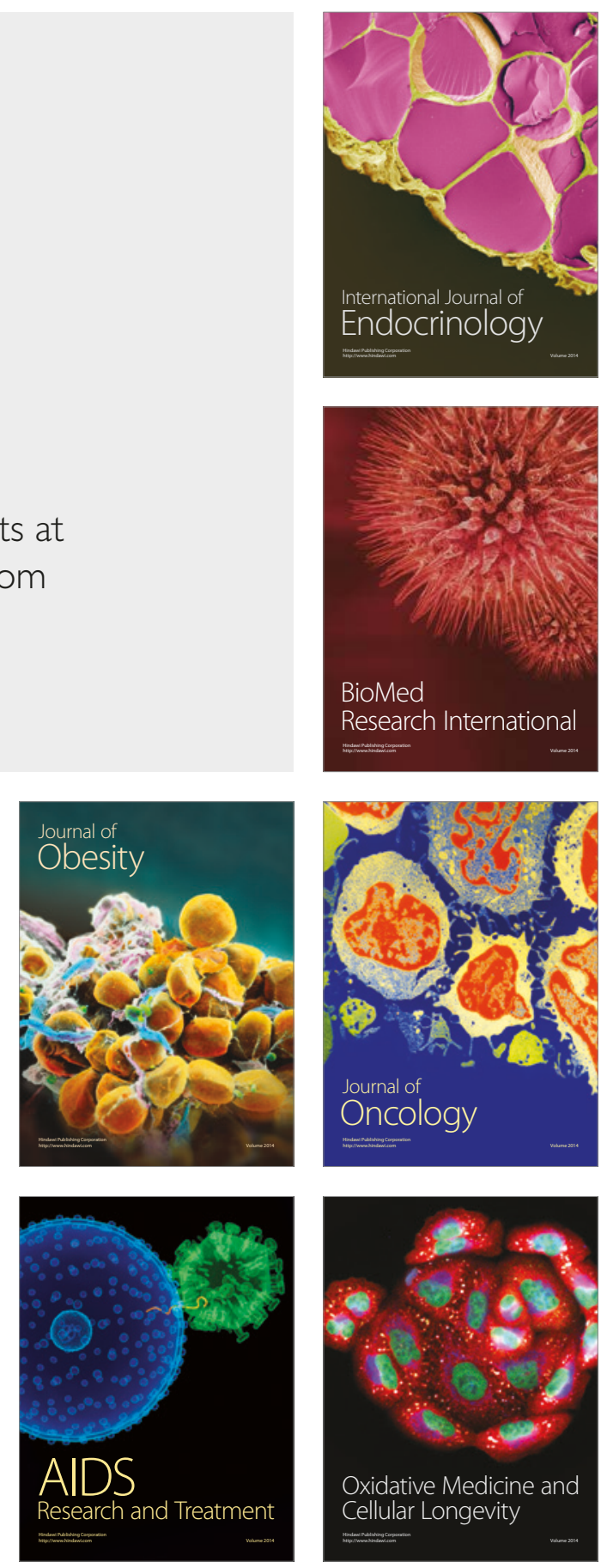